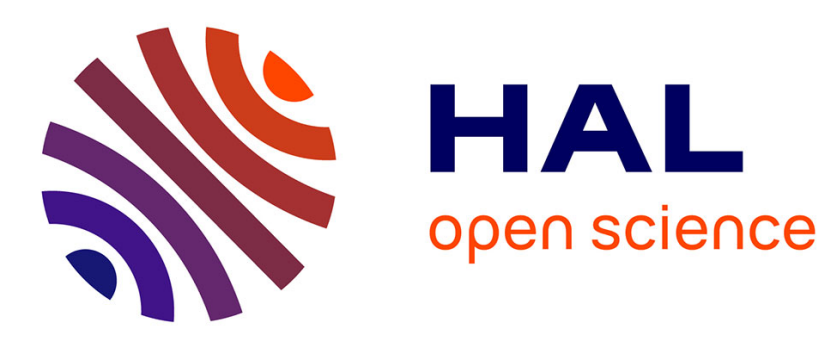

\title{
A Modular Ontology Framework for Building Renovation Domain
}

Prathap Valluru, Janakiram Karlapudi, Teemu Mätäsniemi, Karsten Menzel

\section{To cite this version:}

Prathap Valluru, Janakiram Karlapudi, Teemu Mätäsniemi, Karsten Menzel. A Modular Ontology Framework for Building Renovation Domain. 22nd Working Conference on Virtual Enterprises (PROVE 2021), Nov 2021, Saint-Etienne, France. pp.323-335, 10.1007/978-3-030-85969-5_29 . emse03339305

\section{HAL Id: emse-03339305 https://hal-emse.ccsd.cnrs.fr/emse-03339305}

Submitted on 24 Nov 2021

HAL is a multi-disciplinary open access archive for the deposit and dissemination of scientific research documents, whether they are published or not. The documents may come from teaching and research institutions in France or abroad, or from public or private research centers.
L'archive ouverte pluridisciplinaire HAL, est destinée au dépôt et à la diffusion de documents scientifiques de niveau recherche, publiés ou non, émanant des établissements d'enseignement et de recherche français ou étrangers, des laboratoires publics ou privés. 
Valluru P., Karlapudi J., Mätäsniemi T., Menzel K. (2021) A Modular Ontology Framework for Building Renovation Domain. In: Camarinha-Matos L.M., Boucher X., Afsarmanesh H. (eds) Smart and Sustainable Collaborative Networks 4.0. PRO-VE 2021. IFIP Advances in Information and Communication Technology, vol 629. Springer, Cham. https://doi.org/10.1007/978-3-030-85969-5_29

\title{
A Modular Ontology Framework for Building Renovation Domain
}

\author{
Prathap Valluru ${ }^{1}$, Janakiram Karlapudi ${ }^{1}$, Teemu Mätäsniemi ${ }^{2}$, Karsten Menzel ${ }^{1}$
}

1. Institute of Construction Informatics, Technische Universität Dresden, Dresden, Germany

Prathap.Valluruetu-dresden. de

\{Janakiram.Karlapudi, Karsten.Menzel1\} @tu-dresden.de

2. VTT Technical Research Centre of Finland Ltd, Espoo, Finland

Teemu.Matasniemi@vtt.fi

\begin{abstract}
Building renovation is a complex collaborative process requiring the interaction between planners, architects, civil engineers, energy experts, and managers of (pre-)manufacturing plants supplying building elements, components of energy supply and distribution systems "just in sequence" to densely used urban spaces - where the majority of buildings under renovation are located. Therefore, the availability of a complete, comprehensive Building Information Model, amalgamating current and future product and process models is of outstanding importance. Approaches, suggesting so-called "monolithic" building information models did not deliver the expected "value for money" since the efforts required to set up and maintain such digital models requested more resources than available. Therefore, the authors present in this paper an alternative approach to information, knowledge management, and sharing in the AECO-sector, i.e. modular ontologies. The flexible and dynamic approach to combine new and available modules of information addresses more responsively the needs of the AECO sector. Furthermore, such BIM models overcome limitations in adaptability, extensibility, etc. of current "openBIM models. Due to this the shift towards using semantic web technologies for knowledge base and semantic interoperability has been increased in the AECO industry. The work presented in the paper introduces a recently developed linked data, an ontologybased framework that harmonizes and orchestrates ontologies recently developed for the construction domain. It studies inter-model and inter ontology relationships to address concepts that are currently absent from "building ontologies". The developed framework can be used to support collaborative environments in the engineering and manufacturing sector supporting the efficient sharing of information between architects, engineers, manufacturing plants, and assembly crews on the construction site.
\end{abstract}

Keywords: Ontology composition, renovation process, information sharing/exchange, collaborative networks, Collaborative manufacturing. 


\section{Introduction}

The building renovation process involves stakeholders throughout the life cycle. The stakeholders of the Architecture, Engineering, Construction, and Operations (AECO) industry exchange heterogeneous information among multiple stakeholders, using tools and datasets of different nature [1]. The heterogeneous information includes as-built BIM models, energy information, images, documents, plans, etc. However, the identification of critical information, its management along with the efficient collaboration, and communication between the participants in the project are some barriers in the traditional building construction process [2].

The development of Collaborative Networks (CNs) allows effective collaboration between the teams $[3,4]$ and there is a need to improve the data sharing and management in CNs [5]. The specifications of shared vocabulary can play an important role where knowledge-based systems are expensive to build, test, and maintain [6]. Research work by L.M. Camarinha-Matos et al explained that ontology engineering is a potential domain that can contribute to the information/knowledge management in Collaborative Networks (CNs) [7]. Also, the usage of ontologies in CNs is supported in several research efforts [8-10]. However, the ontologies that can cover construction management data are not available on the web, and also, some existing ontologies cover limited data. There is a need to fill the gaps for entities, construction information, construction activities, stakeholders, level of details, materials, occupants, etc.

In the BIM4EEB ${ }^{1}$ project, several ontologies (Digital Construction Ontologies ${ }^{2}$ DICon) are developed to support the renovation data modeling/sharing and act as a resource to the collaborative system called BIM management system (BIMMS ${ }^{3}$ ). The development of ontologies was carried out by using Web of Data (WoD) technologies. The semantic web and Linked data are two sources of WoD [11]. The semantic web technologies have Resource Description Framework $\left(\mathrm{RDF}^{4}\right)$ model for data interchange, Web Ontology Language $\left(\mathrm{OWL}^{5}\right)$ to represent complex knowledgebase, and Simple Protocol and RDF Query Language (SPARQL ${ }^{6}$ ) to run the queries across the data sets. Linked Data ${ }^{7}$ is to identify things using URIs, look up the name of things using HTTP URIs, add information to the things using semantic web technologies, and link the information to add more context or semantics to existing information.

To make the developed or existing ontologies to be useful, two objectives must be met, as per Barry Smith and Mathias Brochhausen 2008[12]. First, it is essential to align/match existing ontologies by harmonization process. Secondly, it is necessary to find ways to evaluate ontologies transparently. In this paper, we discussed the first part and developed a framework to harmonize the ontologies by modularization approaches.

\footnotetext{
${ }^{1}$ https://www.bim4eeb-project.eu/

${ }^{2} \mathrm{https}$ ://digitalconstruction.github.io/v/0.5/index.html

${ }^{3}$ https://bim4eeb.oneteam.it/BIMMS/Default.aspx

${ }^{4}$ https://www.w3.org/RDF/

${ }^{5}$ https://www.w3.org/OWL/

${ }^{6}$ https://www.w3.org/TR/sparq111-query/

${ }^{7}$ https://www.w3.org/DesignIssues/LinkedData
} 


\section{Ontology Modularization}

Modularization of ontologies will make user easier to understand, extend, reuse, maintain and reason the ontologies $[13,14]$. However, the concept of modularization is not well defined in the context of ontologies compared to software engineering. A single approach for modularization does not match every situation since people tend to have various ideas in the development of ontologies. Several various approaches appeared in the field of ontology modularization. These approaches are mainly categorized into "ontology separation" and "ontologies composition" and are shown in Fig. 1. These two main approaches are sub-categorized into ontology partition, ontology module extraction, ontologies integration, and ontologies mapping respectively [15].

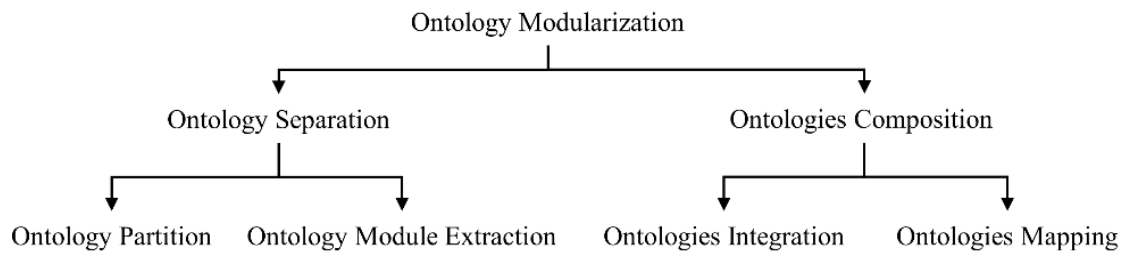

Fig. 1. Ontology modularization approaches

The ontology separation approach is mainly useful to make large-scale ontology into small-scale ontologies to use for narrower use cases. But, in the ontologies composition approach small ontologies will be integrated to make a large ontology by maintaining its modularity. The DICon ontologies cover different domain gaps (e.g. entities, occupant comfort, lifecycle, materials ...etc.). To make it useful for broader domain use cases, ontologies modularization applied on DICon ontologies by using the ontologies composition approach.

\subsection{Ontology Integration}

Ontology integration is the process of forming a new ontology by using one or more ontologies without changing their original concepts, if possible, they are extended [16]. Integrate $\left(\mathcal{O}_{1}, \mathcal{O}_{2}, \mathscr{H}\right)=\mathcal{O}_{1}$, where $\mathrm{O} 1$ is the target ontology into which the source ontology $\mathrm{O} 2$ will be integrated and $\mathrm{A}$ is the alignment expressed in the same logical language as ontologies $\mathrm{O} 1$ and $\mathrm{O} 2$ [17]. Ontology alignment may be seen as a pre-step for detecting where the involved ontologies overlap and can be connected. This approach is especially interesting if given ontologies differ in their domain. Through integration, the new ontology can cover a bigger domain in the end.

In the integration process, two approaches are primarily considered and shown in Fig. 2. The ontologies $\mathrm{O}_{1}, \mathrm{O}_{2}$, and alignment $\mathrm{O}_{1}-\mathrm{O}_{2}$ are considered to discuss these approaches. The Ontology $\mathrm{O}_{1}$, alignment module $\mathrm{O}_{1}-\mathrm{O}_{2}$, are imported to ontology $\mathrm{O}_{2}$ in the first approach, few required concepts from $\mathrm{O}_{1}$ are redefined in the ontology $\mathrm{O}_{2}$. In the second approach, required concepts from ontology $\mathrm{O}_{1}$ are redefined in ontology $\mathrm{O}_{2}$, alignment module $\mathrm{O}_{1}-\mathrm{O}_{2}$ imports ontologies $\mathrm{O}_{1}, \mathrm{O}_{2}$ to extend the scope of usage of ontologies. In this paper, the second approach is considered to develop an ontology framework. 


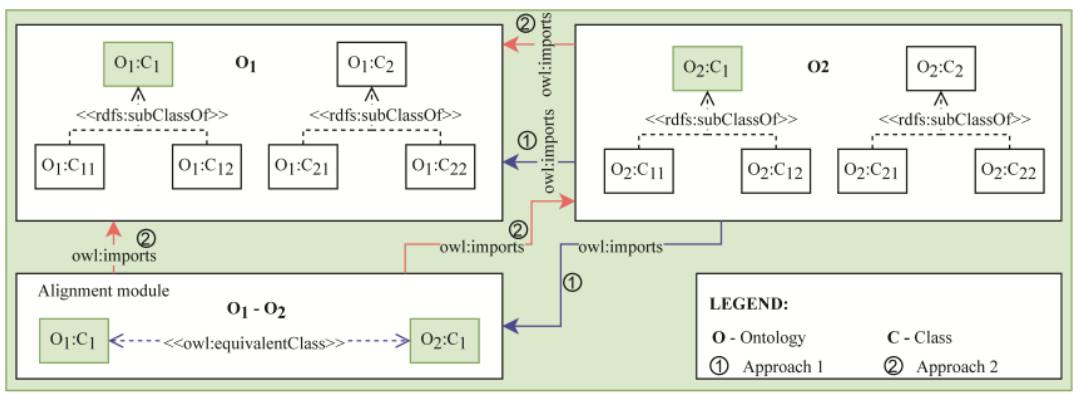

Fig. 2. Ontology integration methods

\subsection{Ontology Mapping}

The mapping is a set of declarative assertions specifying how the sources in the data layer relate to the ontology [18].

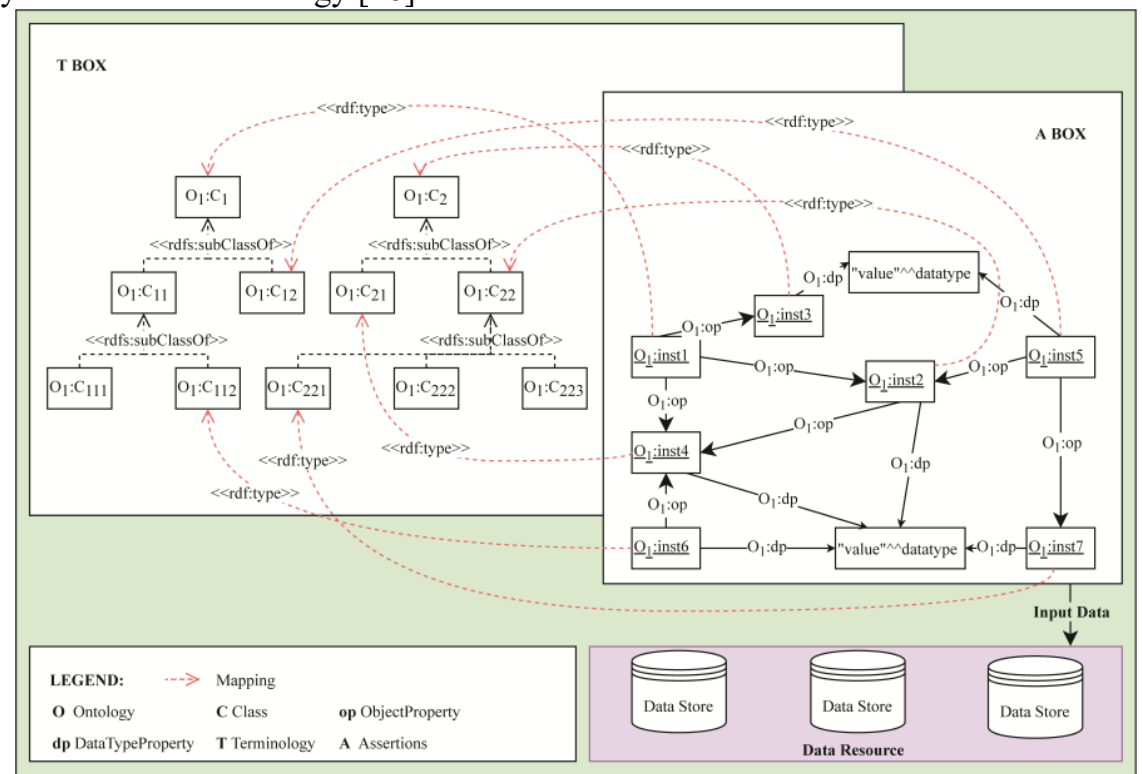

Fig. 3. Ontology Mapping Concept

An ontology mapping represents a function between the ontologies. The original ontologies are not changed, but the additional mapping axioms describe how to express concepts, relations, or instances in terms of the second ontology. They are stored separately from the ontologies themselves [16]. Fig. 3 represents the ontology mapping concept. Three concepts called Terminology Box (T-BOX), Assertion Box (A-BOX), Data sources are considered to explain the ontology mapping process. T-BOX is an ontology with classes, properties, and A-BOX is individual data that comes from the data sources. The individual data that comes from the data sources are mapped with T-BOX 
data and a knowledge base will develop. The axiom rdf:type is used to relate an individual for a class.

\section{Collaborative BIM Environments and Knowledge Base}

For several years, several research initiatives have been focused on the creation and operation of collaborative processes in the construction sector [19]. However, the lack of effective collaborative processes tools, information management of heterogeneous data, and sharing it among the actors are still barriers in AECO sector. Also, lack of tools with integrated Common Data Environments (CDE) [20, 21]. The BIMMS is a collaborative environment developed in the BIM4EEB project. BIMMS is a platform built around a common data environment (CDE) that stores all the data and information gathered through different sources and along the whole building lifecycle, acting as a single source of truth (SSOT) [22].

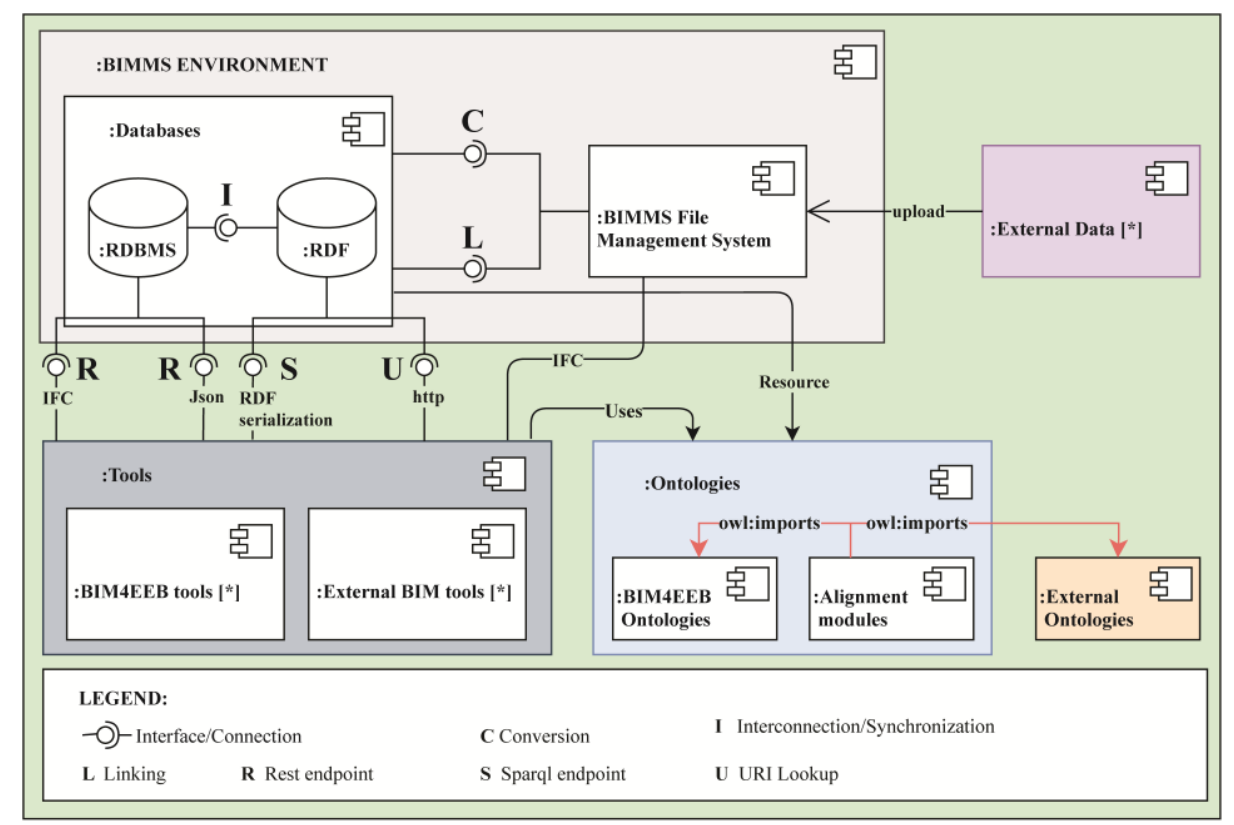

Fig. 4. Usage of modular ontologies in a collaborative environment

The aim of this BIMMS is the effective management of information produced in the renovation processes along with the establishment of efficient communication between the involved tool kits. This process supports the storage of information in various formats (ontologies, models, diagrams, etc.) and manages the information by enabling the links between them. This section intends to explore the ontology-based information management facilities within the BIMMS platform.

A component diagram represented in Fig. 4 comprehensively illustrating the adopted BIM4EEB framework. The involved components in this framework are 1) Ontologies, 
2) BIMMS environment, 3) BIM4EEB tools, and finally, 4) external data (images, files, models, sensor data, etc.). As shown in the figure, the ontology component describes a set of developed ontologies as part of the BIM4EEB project and their alignments to external ontologies in terms of alignment modules. This ontology component is further integrated into BIMMS environment and supports the representation of the BIM model information and other resource information. In specific, the BIMMS system enables this representation by converting the resource data in the File management system into Linked data (RDF data) and Relational Database (RDBMS). It also provides the linkage between these data models or data formats to synchronize the updates or changes effectively. The use of ontologies and linked data in the tools is a promising solution to explore dynamic and heterogeneous data [23].

The last component in the framework is the tool-set, which is used for the progressive and successful implementation of the renovation process. This tool component is equipped either with BIM4EEB tools and/or external tools. The data stored in BIMMS system is effectively shared to these tools based on the required interface connections. In general, there are many interface connections but their application is only dependent on the available data formats and compatibility with the developed tools. In the BIM4EEB framework, APIs like Rest endpoint, SPARQL endpoint, and URI Lookup is used in the data sharing process between the tools and BIMMS system.

\section{$4 \quad$ Modular Ontology Framework}

In the BIM4EEB project, modular ontologies set called Digital Construction Ontologies $\left(\mathrm{DICon}^{8}\right)$ are developed to achieve semantic interoperability and enhance the information sharing and representation of renovation data in the building renovation life cycle process. To expand the scope of ontologies usage, relations are established between the DICon ${ }^{8}$ and external ontologies by using ontology modularization. The developed modular ontology framework consists of two parts. One is ontology integration and the second one is ontology mapping as shown in Fig. 5.

The ontology integration process is explained by considering BIM4EEB ontologies, External ontologies, Alignment Modules. The $\mathrm{O}_{1}$ and $\mathrm{O}_{2}$ conceptually represent BIM4EEB ontologies and $\mathrm{O}_{3}$ represents external ontology, $\mathrm{O}_{1}-\mathrm{O}_{3}$ and $\mathrm{O}_{2}-\mathrm{O}_{3}$ are the alignment modules. To establish a connection between the ontologies three-step approach is followed. In the initial step, removed the overlapping concepts between the BIM4EEB ontologies and imported one ontology to the other. For example, $\mathrm{O}_{1}: \mathrm{C}_{1}$ is a class in $\mathrm{O}_{1}$ and the same class is defined in the ontology $\mathrm{O}_{2}$ with the URI of $\mathrm{O}_{1}$. This approach helps to avoid redundancy and the ontology merging process will be easier. In the second step, alignment modules are developed between the BIM4EEB ontologies and external ontologies and kept as separate files. In the last step, aligned ontologies are imported into its alignment module, which extends the scope of the ontologies. The

\footnotetext{
${ }^{8} \mathrm{https} / / /$ digitalconstruction.github.io/v/0.5/index.html
} 
modular ontologies developed using this integration process are published on the GitHub page https://digitalconstruction.github.io/v/0.5/index.html.

In the second part ontology mapping developed using the concept of "OntologyBased Data Access (OBDA) [24]". The idea behind OBDA is to use a DL ontology as a means to access a set of data sources, to mask the user from all application-dependent aspects of data, and to extract useful information from the sources based on a conceptual representation of the domain, expressed as a T-Box in a suitable DL [25]. The ontologies $\mathrm{O}_{1}, \mathrm{O}_{2}$, and $\mathrm{O}_{3}$ are ontology T Box data, inst:Individual1, inst:Individual2, inst:Individual3, inst:Individual4 are the assertions (A Box data) or data stored in the data resource layer or from the tool. The T-Box data and A-Box data are mapped together using the axioms to form a complete Knowledge Base (KB).

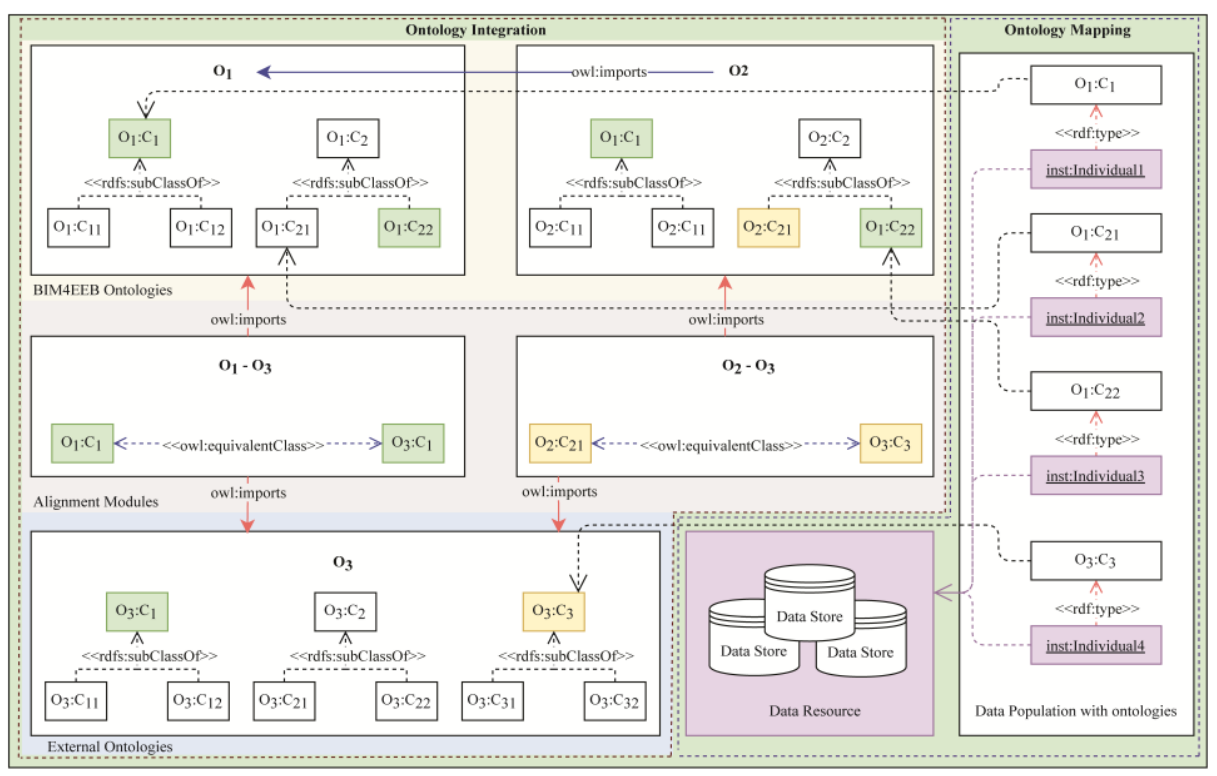

Fig. 5. Modular ontology framework using ontologies composition approach

\section{$5 \quad$ Proof of Concept and Result}

The developed use case is based on the BIMeaser (BIM Early Stage Energy Scenario tool) tool. The BIMeaser was developed for the early phase evaluation of residential building refurbishment designs. This tool able to download BIM models from the BIMMS and Renovation scenarios are defined for simulation, computes the indicators of building energy performance. These indicators are then compared with reference requirements, the Owner's Project Requirements (OPRs). However, the modular ontologies framework is used to establish a relation between the ontologies used to store BIMeaser OPRs. Finally, OPRs calculated with BIMeaser are uploaded into BIMMS in the triple store. Ontologies have been developed and integrated, mapped with the BIMeaser OPRs to develop complete KB. In this process, BIM4EEB ontologies entities 
(DICI), Contexts (DICC), Variable (DICV), Information (DICI), Materials (DICM), and Energy (DICES) are used. Also, the vocabulary Units (DICU) used. The external ontologies Building Topology Ontology (BOT), Quantities, Units, Dimensions and Types $\left(\right.$ QUDT $\left.^{9}\right)$, QUDT UNITS ${ }^{9}$, Data Catalog Vocabulary (DACT ${ }^{10}$ ), PROV Ontology (PROV-O ${ }^{11}$ ), QUDT Quantity Kind ${ }^{9}$. The ontologies are aligned and imported to their respective align modules as shown in Fig. 6. Therefore, BIMeaser provides an effective collaboration tool for experts with different backgrounds in the design team and can speed up decision-making in building refurbishment projects [26].

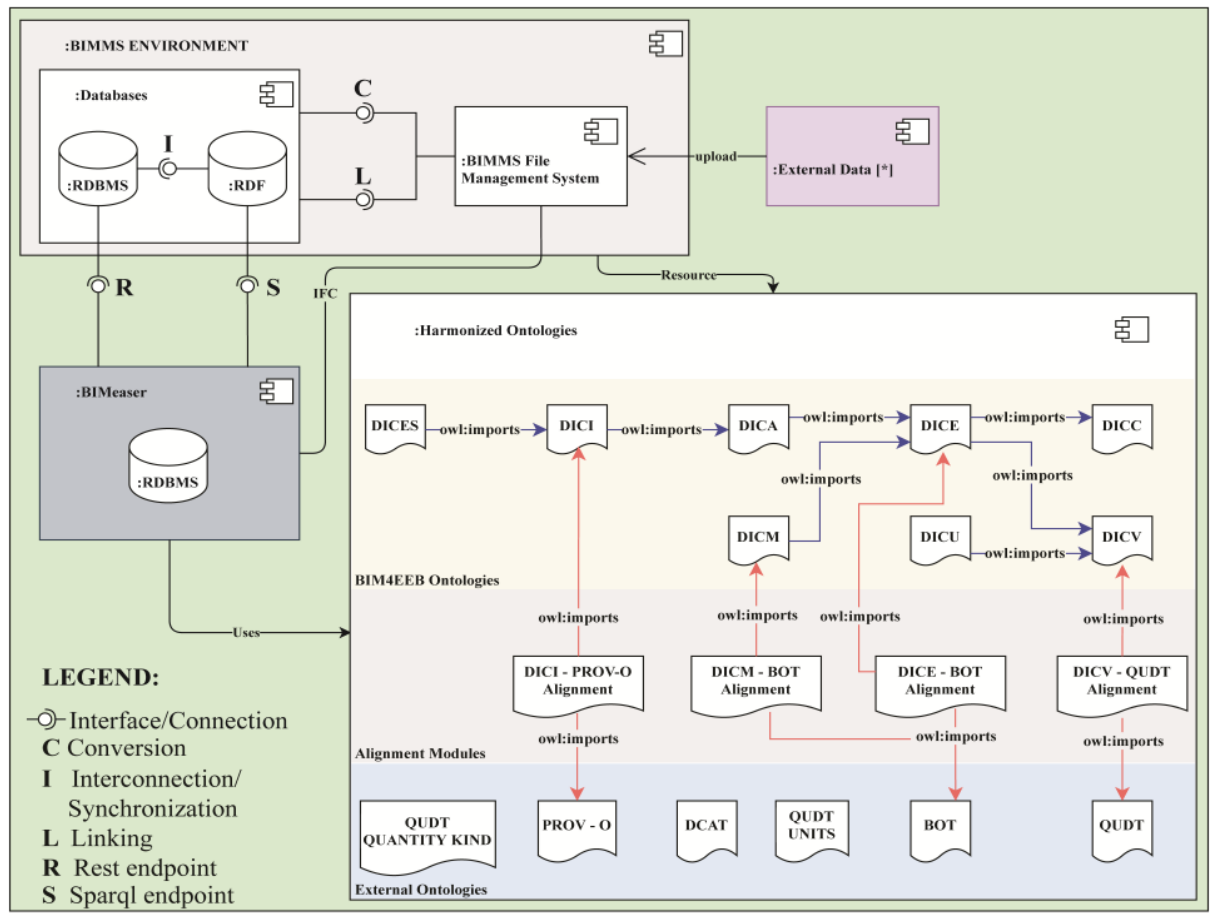

Fig. 6. Usage of modular ontologies in BIMeaser tool

The OPRs for the baseline (no investment cost) and different scenarios are considered and listed in the table below. Each renovation scenario is specified by renovation measures to change building structures or technical systems. The impact of these measures is presented in the terms of Owners Project Requirements (OPR) indicators. The OPR's -e.g. operational energy cost, the payback time of renovation, and summer thermal comfort are an important part of the performance-based building design process, which assumes that design selections are validated against the OPR's in each design stage before moving to the following design stage. The design team will handle the detailed technical energy selections affecting the OPR's using the tool as part of the

\footnotetext{
${ }^{9} \mathrm{http} / / /$ www.qudt.org/pages/QUDToverviewPage.html

${ }^{10} \mathrm{https}: / /$ www.w3.org/TR/vocab-dcat-2/

${ }^{11}$ https://www.w3.org/TR/prov-o/
} 
collaborative work. OPR indicators are computed after detailed building energy simulations based on localized data (e.g. energy and investment cost data). After all, OPRs have been prepared the scenarios can be compared. In a conclusion, BIMeaser presents the impact of each renovation scenario and also baseline results in terms of Owners Project Requirements (OPR). The most important OPR values are calculated to support the performance-based building design process and validation of design decisions.

Table 1. An example of scenario and OPR results presented in BIMeaser tool

\begin{tabular}{|l|l|l|l|l|l|l|l|}
\hline $\begin{array}{c}\text { Sce- } \\
\text { nario }\end{array}$ & $\begin{array}{c}\text { Opera- } \\
\text { tional } \\
\text { energy } \\
\text { cost } \\
\begin{array}{c}\text { floor- } \\
\mathrm{m}^{2}, \mathrm{a}\end{array}\end{array}$ & $\begin{array}{c}\text { Invest- } \\
\text { ment } \\
€ / \text { floor- } \\
\mathrm{m}^{2}\end{array}$ & $\begin{array}{c}\text { RES } \\
\text { share } \\
\%\end{array}$ & $\begin{array}{c}\text { Heating } \\
\mathrm{kWh} / \mathrm{m}^{2}, \mathrm{a}\end{array}$ & $\begin{array}{c}\text { Cooling } \\
\mathrm{kWh} / \mathrm{m}^{2}, \mathrm{a}\end{array}$ & $\begin{array}{c}\text { Electric- } \\
\text { ity } \\
\mathrm{kWh} / \mathrm{m}^{2}, \mathrm{a}\end{array}$ & $\begin{array}{c}\text { Summer } \\
\text { thermal } \\
\mathrm{h} / \text { year,zone } \\
(\text { Tindoor }> \\
\left.27^{\circ} \mathrm{C}\right)\end{array}$ \\
\hline S1 & 14.87 & 0.00 & 0.01 & 123 & 0.0 & 35 & 1763 \\
\hline S2 & 13.39 & 46.41 & 0.01 & 97 & 0.0 & 35 & 2045 \\
\hline S3 & 12.89 & 11.25 & 5.55 & 123 & 0.0 & 26 & 1763 \\
\hline S4 & 13.88 & 16.00 & 0.01 & 106 & 0.0 & 35 & 1763 \\
\hline S5 & 13.60 & 72.18 & 0.01 & 101 & 0.0 & 35 & 1875 \\
\hline S5 & 9.55 & 145.84 & 8.89 & 64 & 0.0 & 26 & 2284 \\
\hline
\end{tabular}

The OPR results are enriched with the classes of the ontologies in BIMeaser tool. These results are converted into an RDF file for data sharing. An example of the OPR data with the ontologies shown in Fig. 7.

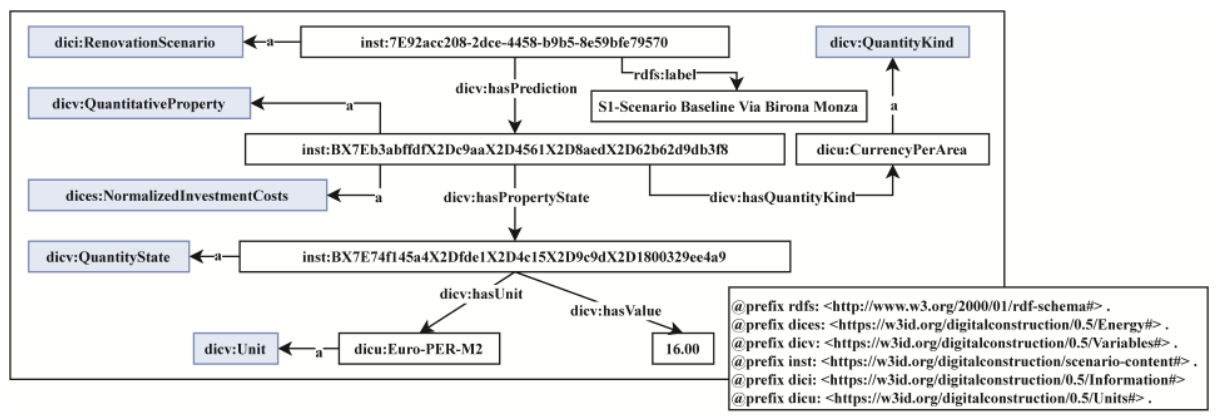

Fig. 7. An example of OPR data in RDF notation

These RDF will be stored in the BIMMS containing links to the IFC model used in the simulation. The linking of OPR's and the BIM model in the BIMMS enables tracking of the building energy performance during the evolution of the renovation design, which is an important part of the performance-based design approach. Also, BIMMS system allows the stakeholder to query and get the required information using the SPARQL Endpoint. For example, the OPR data of heating energy consumption for all renovation scenarios can get from the BIMMS by using the SPARQL query.

\section{SPARQL Query:}

prefix dicv: $<$ https://w3id.org/digitalconstruction/0.5/Variables\#> prefix dices: $<$ https://w3id.org/digitalconstruction/0.5/Energy\#>

prefix dicu: https://w3id.org/digitalconstruction/0.5/Units\# 
prefix inst: $<$ https://w3id.org/digitalconstruction/scenario-content\#>

SELECT ?scenarioName ?Property ?PState ?Value ?Unit

FROM < https://w3id.org/digitalconstruction/scenario-content-opr>

WHERE $\{$ ?scenario dicv:hasPrediction ?Property .

?scenario rdfs:label ?scenarioName .

?Property dicv:isPropertyFor dices:hasNormalizedHeatingEnergyConsumption .

?Property dicv:hasPropertyState ?PState .

?PState dicv:hasValue ?Value .

?PState dicv:hasUnit ?Unit . \}

\section{SPARQL Query Results:}

Fig. 8 shows the query results which are shown by the SPARQL Endpoint in BIMMS. These results are validated with the OPR data (Table 1) presented in BIMeaser tool.

\begin{tabular}{|c|c|c|c|c|}
\hline scenarioName & Property & PState & Value & Unit \\
\hline $\begin{array}{c}\text { "S2-Scenario } \\
\text { Insulation 211a3c72-67df-4f5d- } \\
\text { ae } 45-11 c 3 a e 8 e 6 c 73 "\end{array}$ & $\left|\begin{array}{c}\text { inst:BX7E02748d58X2Dfa92X2D4f } \\
\text { 02X2Daad9X2D4dc5cd3522ea }\end{array}\right|$ & $\begin{array}{c}\text { inst:BX7Eee4a6369X2D0ea4X2D45 } \\
\text { ccX2D999aX2D97ef026943bf }\end{array}$ & 97.0 & $\begin{array}{l}\text { dicu:KiloW-HR- } \\
\text { PER-M2-YR }\end{array}$ \\
\hline $\begin{array}{l}\text { "S1-scenario Baseline via } \\
\text { Birona Monza" }\end{array}$ & $\begin{array}{c}\text { inst:BX7Ea0a2d9fcX2D3888X2D45 } \\
95 \times 2 D 9 b d 9 \times 2 D d 30 d 0 e 51 a 55 c\end{array}$ & $\begin{array}{c}\text { inst:BX7E0fa86f9fX2D73dfX2D46d } \\
\text { cX2Db614X2D7e13c65c0b9d }\end{array}$ & 123.8 & $\begin{array}{c}\text { dicu:KiloW-HR- } \\
\text { PER-M2-YR }\end{array}$ \\
\hline $\begin{array}{c}\text { "S5-Scenario Replacing the } \\
\text { windows 6438aeaf-578b-4d3f-9934 } \\
\text { 68705cdadbeg" }\end{array}$ & $\begin{array}{c}\text { inst:BX7E60b57d94X2D2d96X2D4 } \\
\text { fd2X2Dab7dX2De4e9e50f7b9f }\end{array}$ & $\begin{array}{c}\text { inst:BX7E89a150a7X2D1743X2D42 } \\
\text { e6X2Da2d9X2De174ca256935 }\end{array}$ & 101.0 & $\begin{array}{c}\text { dicu:KiloW-HR- } \\
\text { PER-M2-YR }\end{array}$ \\
\hline $\begin{array}{c}\text { "S3-Scenario Solar PV } \\
\text { panels 4aee83de-5df5-4edb-a3ee- } \\
\text { 1a93bea75477" }\end{array}$ & $\mid \begin{array}{c}\text { inst:BX7Ef22acff9X2Ded7bX2D42 } \\
74 \times 2 D 9730 \times 2 D 3179481 \text { bbb80 }\end{array}$ & $\begin{array}{c}\text { inst:BX7E71b4ccfbX2D86dfX2D439 } \\
3 \times 2 D 99 b 8 \times 2 D 6 a 31 \text { bef47748 }\end{array}$ & 123.0 & $\begin{array}{c}\text { dicu:KiloW-HR- } \\
\text { PER-M2-YR }\end{array}$ \\
\hline $\begin{array}{c}\text { "S6-Scenario 7634d9d3-8a94-4C7a } \\
\text { a2cd-feeea2890a7e" }\end{array}$ & $\begin{array}{c}\text { inst:BX7Eb939fb 70X2D4771X2D4 } \\
072 \times 2 \mathrm{D} 8653 \times 2 \mathrm{D} 7 \mathrm{~b} 397 \mathrm{ccffbaa}\end{array}$ & $\begin{array}{c}\text { inst:BX7E7ae930edX2D5b6eX2D4a } \\
\text { b3X2D9f0dX2D581190637c06 }\end{array}$ & 64.0 & $\begin{array}{c}\text { dicu:KiloW-HR- } \\
\text { PER-M2-YR }\end{array}$ \\
\hline $\begin{array}{c}\text { "S4-Scenario New condensing gas } \\
\text { boiler 92acc208-2dce-4458-b9b5- } \\
\text { 8e59bfe79570" }\end{array}$ & \begin{tabular}{|c|} 
inst:BX7Efc2ac50dX2D3826X2D49 \\
aaX2Da837X2De67e0c07c3fd
\end{tabular} & \begin{tabular}{|c|} 
inst:BX7E98d48f7eX2D8735X2D42 \\
e9X2Da971X2D084824999ca9
\end{tabular} & 106.0 & $\begin{array}{c}\text { dicu:KiloW-HR- } \\
\text { PER-M2-YR }\end{array}$ \\
\hline
\end{tabular}

Fig. 8. SPARQL query results for scenario and OPR data

\section{Conclusion}

The building renovation is a complex process, requires the intervention of stakeholders throughout the renovation. The efficient Collaboration Networks (CNs) equipped with Common Data Environments (CDE) can play a crucial role in the collaboration between the stakeholders in the project. The developed framework will enhance the interoperability between the stakeholders and tools. Ontologies composition approaches have been used to develop the framework. The developed harmonized shared vocabulary will be a resource to the collaboration system and it can be used in the renovation tools for data mapping and representation. A small use case of BIMeaser tool is considered to apply the ontology framework and discussed.

In the future more detailed demonstration of ontologies mapping, data transfer of the other tools using the ontologies, and validation is carried out. 
Acknowledgement: This research is carried out as a part of BIM4EEB project (BIM based fast toolkit for the Efficient rEnovation of Buildings). The BIM4EEB project has received funding from European Union's H2020 research and innovative programme under grant agreement N.820660. The content of this publication reflects author view only and the commission is not responsible for any use that may be made of the information it contains. Finally, we would like to thank Seppo Törma and all partners in the BIM4EEB project for their valuable inputs.

\section{References}

1. Mirarchi C., Lucky M. N., Ciuffreda S., Signorini M., Lupica Spagnolo S., Bolognesi C. et al.: An approach for standardization of semantic models for building renovation processes. In Int. Arch. Photogramm. Remote Sens. Spatial Inf. Sci. XLIII-B4-2020, pp. 69-76, 2020. DOI: 10.5194/isprs-archives-XLIII-B4-2020-69-2020.

2. Valluru P., Karlapudi J., Menzel K., Mätäsniemi T., Shemeikka J.: A Semantic Data Model to Represent Building Material Data in AEC Collaborative Workflows. In Luis M. Camarinha-Matos, Hamideh Afsarmanesh, Angel Ortiz (Eds.): BOOSTING COLLABORATIVE NETWORKS 4.0. 21 st ifip wg 5.5 working, vol. 598. [S.1.]: Springer Nature (IFIP AICT), pp. 133-142., 2021.

3. Camarinha-Matos L.M., Afsarmanesh H. Collaborative Networks. In: Knowledge Enterprise: Intelligent Strategies in Product Design, Manufacturing, and Management. PROLAMAT 2006. IFIP International Federation for Information Processing, vol 207. Springer, Boston, MA . https://doi.org/10.1007/0-387-34403-9_4 (2006).

4. Camarinha-Matos L. M., Afsarmanesh H.: Classes of Collaborative Networks. In: IT Outsourcing: Concepts, Methodologies, Tools, and Applications. IGI Global. pp. 364--370 DOI: 10.4018/978-1-60566-770-6.ch021 (2009).

5. Cristóvão S., Pereira C.: Sharing through Collaborative Spaces: Enhancing Collaborative Networks Interoperability. In: Camarinha-Matos L. M., Afsarmanesh H. (eds.). PROVE2014. IFIP AICT, vol. 434, pp. 481--488 (2014).

6. Thomas R.G.: A translation approach to portable ontology specifications. In Knowledge Acquisition 5 (2), pp. 199-220, 1993. DOI: 10.1006/knac.1993.1008.

7. Camarinha-Matos L.M., Afsarmanesh H.: Collaborative networks in industry and services: research scope and challenges. In IFAC Proceedings Volumes 40 (1), pp. 33-42, 2007. DOI: 10.3182/20070213-3-CU-2913.00007.

8. Aris P., Jakob Axel Bejbro A., Laumann Kjær L., Anja M., McAloone T. C.: Building an Ontology of Product/Service-Systems: using a maritime case study to elicit classifications and characteristics. In: Camarinha-Matos L. M., Afsarmanesh H. (eds.). PRO-VE2014. IFIP AICT, vol. 434, pp. 119--126, (2014).

9. Antonelli D., Bruno G.: Ontology-based framework to design a collaborative human-robotic workcell. In: L.M. Camarinha-Matos et al. (eds.): PRO-VE 2017, IFIP AICT 506, pp. 167-174 (2017).

10. Rachman A., Ratnayake R. C.: Ontology-based semantic modeling for automated identification of damage mechanisms in process plants. In: L. M. Camarinha-Matos et al. (Eds.): PRO-VE 2018, IFIP AICT 534, pp. 457-466, (2018).

11. Törmä, S.: Web of building data - integrating IFC with the Web of Data. In A. Mahdavi, Bob Martens, R. J. Scherer (Eds.): EWork and eBusiness in architecture, engineering and construction. Proceedings 10th European Conf on Product and Process Modelling (ECPPM 2014), Vienna, Austria, 17-19 September 2014. Boca Raton: CRC Press, pp. 141-147, 2015. 
12. Barry S., Mathias B.: Establishing and harmonizing ontologies in an interdisciplinary health care and clinical research environment. 2008.

13. Bernardo G., Ian H., Yevgeny K., Uli S.: A logical framework for modular integration of ontologies. In Proceedings of the 20th International Joint Conference on Artificial Intelligence (IJCAI-07). 2007.

14. Mathieu d'A., Anne S., Heiner S., Marta S.: Criteria and Evaluation for Ontology Modularization Techniques. In Heiner Stuckenschmidt, Christine Parent, Stefano Spaccapietra (Eds.): Modular Ontologies, vol. 5445. Berlin, Heidelberg: Springer Nature (Lecture Notes in Computer Science), pp. 67-89, 2009.

15. Sarra B.A., Andreas S., Thomas M., Mathieu d'A.: Characterizing Modular Ontologies. In CEUR Workshop Proceedings 875, 2012.

16. Marc E.: Ontology Alignment. Bridging the Semantic Gap. Boston, MA: Springer US (Semantic Web and Beyond, Computing for Human Experience, 4), 2007.

17. Inès O., Sadok B.Y., Gayo D.: Ontology Integration: Approaches and Challenging Issues. In Information Fusion 71, pp. 38-63, 2021. DOI: 10.1016/j.inffus.2021.01.007.

18. Floriana Di.P., Giuseppe de. G., Domenico Lembo., Maurizio L., Riccardo R.: Acquiring Ontology Axioms through Mappings to Data Sources. In Future Internet 11 (12), p. 260, 2019. DOI: 10.3390/fi11120260.

19. Keller M., Katranuschkov P., Menzel K.: Modelling collaborative processes for Virtual Organisations in the building industry. In: eWork and eBusiness in Architecture, Engineering and Construction, pp. 417--431, Balkema Publishers (2004).

20. Alreshidi E., Mourshed M., Rezgui Y.: Factors for effective BIM governance. Journal of Building Engineering. pp. 89--101 (2017).

21. Cristóvão S., Pereira C.: Sharing through Collaborative Spaces: Enhancing Collaborative Networks Interoperability. In: Camarinha-Matos L. M., Afsarmanesh H. (eds.). PROVE2014. IFIP AICT, vol. 434, pp. $481--488$ (2014).

22. Alessandro V., Davide M., Jacopo C., Diego F.: The BIM Management System: A Common Data Environment Using Linked Data to Support the Efficient Renovation in Buildings. In Proceedings 65 (1), p. 18, 2020. DOI: 10.3390/proceedings2020065018.

23. Shafahi M., Bart H., Afsarmanesh H.: BioMed Xplorer - Exploring (Bio)Medical Knowledge using Linked Data. In Proceedings of the 9th International Joint Conference on Biomedical Engineering Systems and Technologies - BIOINFORMATICS, (BIOSTEC 2016) ISBN 978-989-758-170-0 ISSN 2184-4305, pages 51-62, 2016. DOI: $10.5220 / 0005700300510062$.

24. Calvanese D., Giacomo G. de, Lembo D., Lenzerini M.: Ontology-based database access. SEBD, 2007.

25. Di Pinto F., Giacomo G. de, Lenzerini M., Rosati R.: Ontology-Based Data Access with Dynamic TBoxes in DL-Lite. The AAAI Conference on Artificial Intelligence (26(1)). Available online at https://ojs.aaai.org/index.php/AAAI/article/view/8223.

26. Shemeikka J., Vesanen T., Hasan A., Mätäsniemi, T.: Early Stage Energy Refurbishment Assessment Tool for Buildings Using High-End BIM Data: Benefits and Challenges. In Proceedings 65 (1), p. 28, 2020. DOI: 10.3390/proceedings2020065028. 